\title{
Job Exposure Matrix (JEM) derived estimates of life-time occupational pesticide exposure and the risk of Parkinson's Disease
}

\author{
Zeyan Liew, MPH ${ }^{\mathrm{a}}$, Anthony Wang, $\mathrm{PhD}^{\mathrm{a}}$, Jeff Bronstein, MD, $\mathrm{PhD}^{\mathrm{b}}$, and Beate Ritz, MD, \\ $\mathrm{PhD}^{\mathrm{a}, \mathrm{b}}$ \\ aDepartment of Epidemiology, Fielding School of Public Health, University of California at Los \\ Angeles, California, USA \\ bDepartment of Neurology, School of Medicine, University of California at Los Angeles, California, \\ USA
}

\section{Abstract}

Studies that report an association between Parkinson's disease (PD) and occupational pesticide exposure often use self-reported exposure and none adjust for concomitant ambient pesticide exposure. For a population-based case-control study of PD conducted in California's heavily agricultural region we developed a comprehensive Job Exposure Matrix (JEM) to assess occupational exposure to pesticides. Relying on 357 incident cases and 750 population controls enrolled between 2001 to 2011 we estimated more than a two-fold risk increase for PD among men classified as highly occupationally exposed. We also observed an exposure-response pattern and farming tasks with direct and intense pesticide exposures such as spraying and handling of pesticides resulted in greater risks than indirect by-stander exposures. Results did not change after adjustment for ambient pesticide exposure. We provide further evidence that occupational pesticide exposure increases the risk of PD.

\section{Keywords}

Case-control study; Job exposure matrix; Occupation; Parkinson's disease; Pesticide exposure

\section{INTRODUCTION}

Parkinson's disease (PD) is the second most common neurodegenerative disorder leading to motor, cognitive and mood dysfunction with a major impact on quality of life. Its etiology is widely considered to be multi-factorial, involving a combination of exposures to neurotoxicants, genetic factors, and aging. ${ }^{1}$ PD has been linked to farm work and pesticide exposures in general ${ }^{2-10}$ with some studies reporting on specific pesticide exposures including our own previous reports focused on ambient pesticides in proximity to agricultural applications. ${ }^{5-9,11-14}$

However, the vast majority of previous epidemiological studies relied on retrospective selfreporting of exposures raising questions about validity due to the possibility of differential recall bias since cases may be more inclined than control subjects to report exposures to suspected toxins as suggested previously. ${ }^{14}$ This German study ${ }^{14}$ found PD risk to be

Correspondence: Address correspondence to Beate Ritz, Department of Epidemiology, Fielding School of Public Health, University of California at Los Angeles, Los Angeles, California, USA, 650 Charles E. Young Drive, Los Angeles, CA 90095-1772, USA. britz@ucla.edu. 
increased with self-reported pesticide use but not when a job exposure matrix was employed to assess pesticide exposures. Few studies utilized methods less influenced by subject recall such as exposure matrices or expert evaluations based on job history to assess occupational pesticide exposures but most of these studies were either very small ${ }^{4,15}$ ( $<90$ incident PD cases) or they solely classified subjects as ever/never exposed based on job titles. ${ }^{14,16-19} \mathrm{~A}$ French study ${ }^{12}$ is perhaps the most comprehensive to date in terms of occupational pesticide exposure assessment as occupational practitioners interviewed participants and conducted in-depth evaluations of exposure histories. However, this study was still relatively small and additional information from studies employing a job exposure matrix is needed to expand the existing literature.

Our study participants reside in one of the most agriculturally intensive regions in the United States where $\sim 65$ million pounds of pesticide active ingredients were sprayed in 2009 (CDPR summary of pesticide use report data 2009). ${ }^{20}$ This is our first report on lifetime occupational exposure to pesticides derived from a job exposure matrix in our PD case control study in the Central Valley of California. Previously, we focused solely on ambient pesticides exposure in proximity to agricultural applications which we also accounted for in some of the analyses presented here.

\section{MATERIALS AND METHODS}

All procedures described have been approved by the University of California at Los Angeles, Institutional Review Board for human subjects, and informed consent was obtained from all participants.

\section{Study population}

We conducted a population- based case-control study of PD in a largely agricultural region in California's Central Valley and collected work histories to assess occupational pesticide exposures relying on a job exposure matrix approach. We enrolled incident idiopathic PD patients from 2001 to 2007 and population-based controls from three mostly rural agricultural counties (Kern, Tulare, Fresno) in central California from 2002 to early 2011. Details of subject recruitment methods ${ }^{6,8}$ and case definition criteria ${ }^{21,22}$ have been described elsewhere.

Of 1,167 PD patients who initially responded to an invitation through neurologists, large medical groups, and public service announcements, 604 were not eligible: 397 had been diagnosed more than 3 years prior to contact, 134 lived outside the tri-county area at the time of recruitment, 51 had a diagnosis other than PD, and 22 were too ill to participate. Eligible cases were examined at least once and most multiple times by movement disorder specialists from the University of California at Los Angeles to confirm PD diagnoses. Of the 563 eligible cases, 90 could not be examined (56 declined to participate or moved away, 18 had become too ill to be examined, and 16 died prior to the scheduled appointment). Of the 473 subjects examined, 94 did not meet published criteria for idiopathic $\mathrm{PD}^{23,24}$ when examined or re-examined by movement disorder specialists during the initial study period, an additional 13 were reclassified as not having idiopathic PD during our follow-up study, 25 and 6 subjects withdrew between examination and interview. Of the remaining 360 cases, 357 provided all information including work history necessary for inclusion in this analysis.

Population-based controls were recruited initially from Medicare lists (2001) and, after the Health Insurance Portability and Accountability Act (HIPAA), from residential tax assessor records from the tri-county area. Controls recruitment eligibility criteria were similar to cases : 1) age 35 or older; 2) not too ill to participate; 3) had lived in California for 5 years prior to enrollment; 4) currently residing primarily at the selected residence; and 5) not 
being diagnosed with PD (not for cases). Two sampling strategies were implemented to increase enrollment success and achieve representativeness of the control population. First between 2001 and 2007, we randomly selected residential parcels and enrolled control subjects via mail and phone only (Details have been described in Costello et $\mathrm{al}^{6}$ ). For our second control recruitment effort (2009-2011), we again selected parcels presumed to be residential units at random from tax assessors maps but this time identified a group of five residences each clustered in close proximity to each other for at the door-step recruitment. Thus, our trained field staffs who determined eligibility and enrolled controls during home visits had the opportunity to enroll as many as five controls in neighboring homes - if found eligible - at each visit. Each household was approached up to four times on weekdays and weekends. Only one member per household was allowed to enroll.

Of the 1,212 potential controls contacted through the first sampling strategy, 457 were ineligible: 409 were too young $(<35), 44$ were too ill to participate, and 4 primarily resided outside the study area. From 755 eligible population controls, 409 declined, became too ill to participate, or moved out of the study area after screening and prior to enrollment; a total of 346 population controls enrolled from the first sampling strategy. Of the 4,756 individuals screened for eligibility through the second sampling strategy, 3,515 were ineligible (88\% due to age criteria). 1,241 population controls from second sampling were found to be eligible but 634 declined participation; 607 population controls enrolled, but 183 of those controls completed only an abbreviated questionnaire. In sum, 341 from first sampling and 409 from second sampling with a total of 750 controls provided all information including work history needed for following analyses.

\section{Job Exposure Matrix}

Trained interviewers blinded to case/control status conducted structured telephone interviews to obtain demographic and work history information such as job title, job task, company, industry, address, and duration of work (years), and hours worked per week from study participants.

We coded information on jobs and industries in 26 major occupational categories according to the Integrated Public Use Microdata Series (IPUMS-USA) 2000 Occupation Code System. ${ }^{26}$ Only jobs in which a subject had worked for 6-months or more throughout their lifetime were assessed. We created a job exposure matrix (JEM) to estimate occupational pesticide exposure based on work history information from job titles, job tasks and duration of work. We estimated the likelihood that an occupational exposure to pesticides had occurred in an approach similar to Young et al. ${ }^{27}$ Job tasks were assigned weights to reflect intensity of likely pesticide exposure. Jobs unrelated to farming and those not known to involve occupational pesticide handling received a weight of zero, while pesticide-specific tasks were given corresponding standard weights [in brackets]: pesticide mixing [1.0], pesticide application [0.9], planting and ploughing [0.5], general fieldwork [0.3], nonfieldwork farming tasks [0.05], farming management, supplies and transportation [0.01].. Due to concerns that our effect measures may be sensitive to how the weights were chosen, we compared the standard weights to two other weighting schemes one we called "conservative weighting" (lower weights assigned for general farmwork, non-fieldwork, and farming supplies job tasks), and another we called "maximum weighting" emphasizing tasks with likely high intensity exposures (see Table E-1 for details).

When a job involved multiple tasks that received different weights, we constructed an average weight across all tasks performed in this job. Years a subject reported having worked in a job multiplied by each weight were summed across all jobs reported to construct a lifetime cumulative measure of occupational pesticide exposure for each participant (see Table E-2 for examples). 


\section{Statistical Analysis}

We used SAS 9.2 (SAS Institute Inc., Cary, NC, USA) to perform unconditional logistic regression analyses. We adjusted for age at diagnosis (cases) or age at interview (controls), sex, ethnicity (White vs. non-White), education (< 12 years, 12 years, $>12$ years), having a $1^{\text {st }}$ degree family member with PD (yes, no), and smoking (current, former, never). Based on percentiles from the exposure distribution in controls using the JEM-derived lifetime cumulative occupational pesticide measure we considered participants as unexposed, or if falling above 0 and below the $25^{\text {th }}$ percentile as low, 26-75 above the $75^{\text {th }}$ percentile as highly exposed.

Moreover, we considered participants who reported ever performing the job tasks of mixing and applying/spraying of pesticides as directly exposed to pesticides and those who reported having held farming jobs with tasks other than pesticide mixing and application as likely indirectly exposed.

\section{Sensitivity Analysis}

In addition, in sensitivity analyses we stratified our main analyses by gender, excluded a) Hispanics, b) participants less than age 50, and c) restricted control groups from the first or second sampling separately. Moreover, we employed adjustment for pack-years of smoking and for self-reported regular work with metals, wood, chemical solvents, and paint strippers to address potential confounding by farming related exposures other than pesticides. We also investigated whether our JEM-derived exposure measures were sensitive to reported hours of work per week in each job. While most jobs were reported as 40 hours per week (full time) positions, we used additional weights to adjust for having held part time jobs (i.e. dividing the reported hours per week by 40); this procedure increased the exposure score for those working more than 40 hours and reduced it for part time jobs. Since $15 \%$ of all reported farm-related jobs did not report hours per week, we imputed the missing hours based on the average hours a subject reported working in all other jobs or alternatively assumed they had worked 40 hours per week.

Moreover, we adjusted our JEM-derived measures also for residential and occupational pesticide exposures based on our Geographic Information System (GIS) model that provides ambient exposure measures for addresses within 500 meter from pesticide applications recorded in the California Pesticide Use Reporting system during 1974-1999. Details have been described elsewhere ${ }^{6,8}$. We used indicator variables for ever/never exposure to four types of pesticides (organochlorines (OC), organophosphates (OP), dithiocarbamates (DTC) and paraquat (PQ)) that have been suggested to be linked to dopaminergic cell damage and possibly PD, ${ }^{28}$ or we adjusted based on a propensity score that regressed the JEM-derived exposure estimate onto the indicators of ever/never exposure to residential and occupational ambient pesticide exposure and other key covariates included in main analysis.

\section{RESULTS}

Study participants were predominantly white, over the age of 60 , and did not have a family history of PD (Table 1). Cases were slightly older than controls, more frequently male, and also reported to have smoked less than controls.

The distribution of occupational histories (jobs held $>6$ months at any time in life) by case status categorized according to the IPUM-USA 2000 occupational codes classification are shown in Table 2 . The most commonly reported occupations among study populations were office/administrative support (34\%), followed by farming/fishing/forestry (29\%), and management occupations (28\%). In our data, more cases had been employed in farming and military occupations (male dominated jobs), and more controls in education/training and 
food preparation related occupations (female dominated jobs) as expected due to the predominance of PD among males. Job tasks reported by those who had held agricultural jobs included: fieldwork and general tasks (25.2\%), non-fieldwork related farming tasks $(10.7 \%)$, planting/ploughing, pesticide application/spraying, transportation/farming supplies $(2-3 \%)$, and only 3 men reported mixing of pesticides as a task (see Table 3 ). Also as expected, all of these farming tasks were mostly performed by men.

Based on our JEM-derived life-time cumulative occupational pesticide exposure estimates, we calculated a $55 \%$ increase in the risk of developing $\mathrm{PD}$ with high $(\mathrm{OR}=1.55$; 95\% CI: $0.96-2.51), 28 \%$ with medium ( $\mathrm{OR}=1.28$; 95\%CI: 0.87-1.87), and no association with low pesticide exposure (OR=1.00; 95\%CI: 0.59-1.69) (Table 4). Estimated effects were much stronger for males, with a $119 \%$ risk increase with high $(\mathrm{OR}=2.19 ; 95 \% \mathrm{CI}: 1.26-3.82)$, a $68 \%$ increase with medium $(\mathrm{OR}=1.68 ; 95 \% \mathrm{CI}: 1.02-2.74)$, and no association with low exposure $(\mathrm{OR}=1.16 ; 95 \% \mathrm{CI}$ : 0.60-2.24). Conversely, no associations were observed for women who were exposed $(\mathrm{OR}=0.83 ; 95 \% \mathrm{CI}$ : $0.50-1.40)$ but these estimates were based on very small numbers (only 3 female cases and 15 female controls were considered highly exposed).

Our results based on alternative conservative or maximum weights for specific job tasks were quite consistent with the results using standard weights to create our JEM measures. Since we recruited more Hispanics residents in our second home visit based control sampling, we also performed sensitivity analyses excluding Hispanics. Results were very similar to those presented (i.e. for highly exposed non-Hispanic males $\mathrm{OR}=2.05$; $95 \% \mathrm{CI}$ : 1.08-3.91). No difference was observed in analyses excluding younger participants less than age 50 or adjusting for pack-years of smoking in model. Reported associations did not change in additional sensitivity analyses that adjusted for other farming related exposures such as regular work with metals, wood, chemical solvents and paint strippers, or that incorporated weights for hours worked per week in each job (see Table E-3). Additionally, reported associations also did not change when we adjusted in addition for ambient residential pesticide exposures in our models (see Table 5). However, effect estimates were slightly attenuated with adjustment for ambient pesticide exposures at workplaces (JEM derived highly exposed males versus unexposed $\mathrm{OR}=1.95 ; 95 \% \mathrm{CI}$ : 1.09-3.49).

Moreover, we estimated that presumed direct exposures (ever mixed, applied or sprayed pesticides) increased risk of PD in males by 2 fold (OR=2.00; 95\%CI: $0.92-4.37)$ and presumed indirect exposures (ever performed farming job tasks other than pesticides mixing and application)by about 62\% (OR=1.62; 95\%CI: 1.08-2.43) (Table 6).

\section{DISCUSSION}

We conducted a population-based case-control study of PD in a largely agricultural region of Central California confirming previous reports that occupational exposures to pesticides in farming related jobs increase the risk of developing PD. In fact, we found an exposure response trend for PD with intensity of life-time cumulative pesticide exposures based on JEM derived measures. We also found that presumed direct exposures to pesticide (e.g. applying, spraying and mixing of pesticides) resulted in greater risk of PD compared to indirect exposures from farming work. Our results for occupational pesticide exposures are restricted to men in our population. Not only were few women engaged jobs exposing them to pesticides in this study, those women who may have worked with and around pesticides may still have been exposed to a different degree since our study was unable to capture for example type of pesticides and personal protective equipment use. It is also possible that men are more vulnerable to pesticide exposure than women although this is not supported by other studies. 6,8 
Past epidemiologic studies have linked farming in general to PD risk, ${ }^{3,29-31}$ and some suggested that specific occupational pesticide exposures are responsible for PD in farmers. ${ }^{5,7,14} \mathrm{~A}$ most recent meta-analysis that reviewed 46 previous studies reported a summary risk ratio of $\mathrm{RR}=1.52$ (95\% CI: $1.23-1.88$ ) for PD and Parkinsonism and occupational exposure to any pesticide, and a $\mathrm{RR}=1.62$ (95\%CI: $1.40-1.88)$ for combined occupational and non-occupational pesticide exposure. ${ }^{32}$ Among PD case-control studies, a majority however relied on retrospectively self-reported occupational pesticide exposures, with only a few ${ }^{4,12}$ estimating occupational pesticide exposures solely based on expert assessment and job-titles to construct exposure matrixes, underscoring a lack of studies using exposure assessment methods that might not be affected by recall bias. A small casecontrol study conducted in southwest of France ${ }^{4}$ took an approach similar to our study developing a life-time occupations JEM with the help of occupational health professionals and reported ever occupational pesticide exposure to be associated with PD $(\mathrm{OR}=2.2$; 95\%CI: 1.1-4.3). However, this study failed to find any exposure-response for life-time cumulative pesticide exposure and PD, possibly due to the small number of exposed cases (only 2 highly and 7 moderately exposed cases). Another more recent French study ${ }^{12}$ used case-by-case expert evaluation for exposure assessment; here professional pesticide use was positively associated with $\mathrm{PD}(\mathrm{OR}=1.8 ; 95 \% \mathrm{CI}$ : $1.1-3.1)$ and an exposure-response with number of years use was also observed.

Few cohort studies investigated the impact of occupational pesticide use on PD. ${ }^{3,9,10,15}$ Two studies ${ }^{10,15}$ were not informative for professional pesticide exposures due to the small number of exposed cases with PD. The Honolulu-Asia Aging Study (HAAS) ${ }^{3}$ employed a simple metric of years working on sugarcane or pineapple plantations and reported that men who had worked for more than 20 years approximately doubled their risk for PD ( $R R=1.9$; 95\%CI: 1.0-3.5). To date, the most comprehensive study on occupational pesticide use is the Agricultural Health Study (AHS) cohort of licensed pesticide applicators and their spouses. This study recently reported an increased risk for PD with self-reported cumulative days of pesticide use $(\mathrm{OR}=2.3 ; 95 \% \mathrm{CI}: 1.2-4.5)^{9}$.This study investigated specific pesticide use but did not find any specific compounds or functional groups to be more than weakly associated with incident PD, possibly due to the small number of cases ( $\mathrm{n}=78$ incident cases) and the large number $(\sim 50)$ of chemicals participants were asked to self-report exposure. More recently, a small case controls study of $110 \mathrm{PD}$ cases nested within this cohort ${ }^{7}$ reported increased $\mathrm{PD}$ risk for exposure to rotenone $(\mathrm{OR}=2.5 ; 95 \% \mathrm{CI} 1.3-4.7)$ and any pesticides thought to inhibit mitochondrial complex I (OR=2.0; 95\%CI: 1.2-3.6), as well as for exposure to paraquat $(\mathrm{OR}=2.5 ; 95 \% \mathrm{CI}$ : $1.4-4.7)$ or any oxidative stressors $(\mathrm{OR}=1.7$; 95\%CI: 1.0-2.8). While these results are consistent with some of our previous findings for specific ambient pesticides in Central California based on pesticide use report records, 6,8 this nested case control study did not collect exposure data from baseline and prior to disease occurrence therefore might suffer from the same differential recall bias as any case control studies that employed retrospective exposure assessment and subjects self-reported pesticides use.

Exposure assessment in case-control studies of chronic diseases with a long latency like PD is challenging because exposures usually have to be assessed retrospectively and for many years before the disease occurs. As mentioned above, differential and non-differential recall bias are both major concerns since PD cases may over-report exposures and agricultural workers in general may not remember what chemicals they applied to fields, ${ }^{33}$ or the chemical names or frequency of application. ${ }^{4}$ In addition, self-reported pesticide exposures do not account for exposures in those who do not actively apply pesticides but are nevertheless potentially indirectly exposed to pesticides from drift and working in fields previously treated. ${ }^{34} \mathrm{~A}$ major strength of our study is the use of a job exposure matrix to uniformly and blindly estimate occupational pesticide exposure based on comprehensive 
lifetime occupational histories. Most likely it is easier for subjects to recall job titles and tasks than specific pesticide compounds. ${ }^{35}$ Differential recall bias may still arise if cases spent more effort to recall details of job tasks during their occupation history interviews, but we found that frequency and duration of reported occupations was comparable in our case and control participants.

Another important strength of our study is that unlike previous studies we were able to account for background ambient pesticide exposures due to working on or living near farms. To our knowledge, we are the first study to show that after adjusting for ambient residential and occupational pesticide exposures as well as other PD risk factors, pesticide exposures estimated through life-time farming job history remain a strong risk factor for PD. Interestingly but not unexpectedly, our measures of ambient occupational but not residential exposures derived from GIS models using reported workplace addresses correlated moderately with our JEM-derived occupational exposure measures based on job titles and job tasks. In addition, we estimated a greater PD risk increase in those more directly exposed via handling or applying pesticide which provides additional evidence for the role of pesticide exposure over other farming related activities that result in exposures to solvents, fuels, dusts, micro-organisms that have been suggested as contributing to PD risk in farmers. ${ }^{36,37}$ This is further supported by our finding that estimated effects did not change when we adjusted for self-reported regular work with metals, wood, chemical solvents, and paint strippers.

In line with previous studies, ${ }^{12,15,18}$ we found a PD risk increase only in men and not women occupationally exposed to pesticide. However, our previous studies in Central Valley California that used GIS and pesticide use reports to investigate ambient pesticide exposures due to living or working near pesticide applications did not observe exposure and PD risk differences by gender. ${ }^{6,8}$ This contrast might be due to differences in exposure patterns by gender such that men are more likely to be exposed to pesticides through performing the more strenuous farming tasks involving pesticide mixing, spraying, and planting in the field, whereas ambient exposures from living or working in proximity to agricultural applications would be expected to not vary by gender.

Our study is to date the only study in which movement disorder specialists examined patients multiple times to confirm diagnoses, thus largely reducing disease misclassification. Moreover, our study enrolled a relatively large number of PD cases compared to previous studies that also used expert evaluations to assess occupational pesticide exposure. Finally, as farming is the second most common occupation in the tri-county area, the prevalence of occupational pesticide exposure in our study was sufficiently high to detect moderate size associations.

A limitation of our study is that we did not record usage of personal protective equipments with the occupational history which might modify pesticide exposure levels. ${ }^{38,39}$ Moreover, our study does not provide evidence for the association between PD and specific pesticides due to the limits of a JEM measuring exposures to specific compounds. Exposure misclassification is another concerns using a JEM because the same exposure level is being assigned to everyone reporting similar job tasks, yet in reality other factors such as methods of application and the physical or chemical properties of different pesticides may influence the true amount of pesticide exposure to farm workers. ${ }^{40,41}$ However, this exposure misclassification is likely to be non-differential by case status and may have biased effect estimates towards the null. Since our study was conducted in an area with substantial agricultural pesticide use, study results may not be generalizable to farming populations with less intensive pesticide use or using pesticides other than those applied in Central California. 
As in any case control study with less than perfect participation rates, bias may occur if cases and controls selected themselves into a study according to their potential for pesticide exposure. Our first group of controls were recruited by mail and phone and responders tended to be somewhat more educated than cases which allows for the possibility that we enrolled less population controls potentially exposed to pesticides occupationally from farming. However, our second control group was recruited in a door-to-door approach and control participants were more likely to be of Hispanic origin and to have less formal education, i.e. they were indeed more representative of our source population in Central California. Our results however did not change when we compared our cases to either the first or the second control group separately, or excluded all Hispanics participants.

In conclusion, our study suggests that PD risk increases in men with higher lifetime cumulative pesticide exposure from farming-related jobs, as well as performing job tasks that were related to more direct and possibly intense pesticide exposures in the highly agricultural California Central Valley, even after controlling for ambient pesticide exposures.

\section{Acknowledgments}

\section{Funding}

This work was supported by the National Institute of Environmental Health Science [grant numbers [R01ES010544, U54ES012078, P01-ES016732] and the National Institute of Neurological Disorders and Stroke [grant number P50NS038367]; in addition, initial pilot funding was provided from NIH P30ES007048 and a pilot grant by the American Parkinson Disease Association.

The authors thank the participants of this study and the neurologist community of the Central Valley of California for their continued support, Dr. M. Cockburn for lending his GIS expertise, J. Qiu for helping in SAS programming, all interviewers, and staffs who prepared databases for this study.

\section{References}

1. Wirdefeldt K, Adami H-O, Cole P, Trichopoulos D, Mandel J. Epidemiology and etiology of Parkinson's disease: a review of the evidence. Eur J Epidemiol. 2011; 26:1-58. [PubMed: 20845063]

2. Priyadarshi A, Khuder SA, Schaub EA, Priyadarshi SS. Environmental risk factors and Parkinson's disease: a metaanalysis. Environ Res. 2001; 86:122-127. [PubMed: 11437458]

3. Petrovitch H, Ross GW, Abbott RD, et al. Plantation work and risk of Parkinson disease in a population-based longitudinal study. Arch Neurol. 2002; 59:1787-1792. [PubMed: 12433267]

4. Baldi I, Cantagrel A, Lebailly P, et al. Association between Parkinson's disease and exposure to pesticides in southwestern France. Neuroepidemiology. 2003; 22:305-310. [PubMed: 12902626]

5. Liou HH, Tsai MC, Chen CJ, et al. Environmental risk factors and Parkinson's disease: a casecontrol study in Taiwan. Neurology. 1997; 48:1583-1588. [PubMed: 9191770]

6. Costello S, Cockburn M, Bronstein J, Zhang X, Ritz B. Parkinson's Disease and Residential Exposure to Maneb and Paraquat From Agricultural Applications in the Central Valley of California. Am J Epidemiol. 2009; 169:919-926. [PubMed: 19270050]

7. Tanner CM, Kamel F, Ross GW, et al. Rotenone, paraquat, and Parkinson's disease. Environ Health Perspect. 2011; 119:866-872. [PubMed: 21269927]

8. Wang A, Costello S, Cockburn M, Zhang X, Bronstein J, Ritz B. Parkinson's disease risk from ambient exposure to pesticides. Eur J Epidemiol. 2011; 26:547-555. [PubMed: 21505849]

9. Kamel F, Tanner C, Umbach D, et al. Pesticide exposure and self-reported Parkinson's disease in the agricultural health study. Am J Epidemiol. 2007; 165:364-374. [PubMed: 17116648]

10. Ascherio A, Chen H, Weisskopf MG, et al. Pesticide exposure and risk for Parkinson's disease. Ann Neurol. 2006; 60:197-203. [PubMed: 16802290] 
11. Dhillon AS, Tarbutton GL, Levin JL, et al. Pesticide/environmental exposures and Parkinson's disease in East Texas. J Agromedicine. 2008; 13:37-48. [PubMed: 19042691]

12. Elbaz A, Clavel J, Rathouz PJ, et al. Professional exposure to pesticides and Parkinson disease. Ann Neurol. 2009; 66:494-504. [PubMed: 19847896]

13. Hancock DB, Martin ER, Mayhew GM, et al. Pesticide exposure and risk of Parkinson's disease: a family-based case-control study. BMC Neurol. 2008; 8:6. [PubMed: 18373838]

14. Seidler A, Hellenbrand W, Robra BP, et al. Possible environmental, occupational, and other etiologic factors for Parkinson's disease: a case-control study in Germany. Neurology. 1996; 46:1275-1284. [PubMed: 8628466]

15. Baldi I, Lebailly P, Mohammed-Brahim B, Letenneur L, Dartigues JF, Brochard P. Neurodegenerative diseases and exposure to pesticides in the elderly. Am J Epidemiol. 2003; 157:409-414. [PubMed: 12615605]

16. Li X, Sundquist J, Sundquist K. Socioeconomic and occupational groups and Parkinson's disease: a nationwide study based on hospitalizations in Sweden. Int Arch Occup Environ Health. 2009; 82:235-241. [PubMed: 18427829]

17. Hertzman C, Wiens M, Snow B, Kelly S, Calne D. A case-control study of Parkinson's disease in a horticultural region of British Columbia. Mov Disord. 1994; 9:69-75. [PubMed: 8139607]

18. Tuchsen F, Jensen AA. Agricultural work and the risk of Parkinson's disease in Denmark, 19811993. Scand J Work Environ Health. 2000; 26:359-362. [PubMed: 10994803]

19. Dick S, Semple S, Dick F, Seaton A. Occupational titles as risk factors for Parkinson's disease. Occup Med (Lond). 2007; 57:50-56. [PubMed: 17046990]

20. [Accessed May 2012.] CDPR summary of pesticide use report data 2009. http://www.cdpr.ca.gov/ docs/pur/pur09rep/lbsby_co_09.pdf

21. Jacob EL, Gatto NM, Thompson A, Bordelon Y, Ritz B. Occurrence of depression and anxiety prior to Parkinson's disease. Parkinsonism Relat Disord. 2010; 16:576-581. [PubMed: 20674460]

22. Kang GA, Bronstein JM, Masterman DL, Redelings M, Crum JA, Ritz B. Clinical characteristics in early Parkinson's disease in a central California population-based study. Mov Disord. 2005; 20:1133-1142. [PubMed: 15954133]

23. Hughes AJ, Ben-Shlomo Y, Daniel SE, Lees AJ. What features improve the accuracy of clinical diagnosis in Parkinson's disease: A clinicopathologic study. Neurology. 2001; 57:S34-S38. [PubMed: 11775598]

24. Langston JW, Widner H, Goetz CG, et al. Core assessment program for intracerebral transplantations (CAPIT). Mov Disord. 1992; 7:2-13. [PubMed: 1557062]

25. Ritz B, Rhodes SL, Bordelon Y, Bronstein J. alpha-Synuclein Genetic Variants Predict Faster Motor Symptom Progression in Idiopathic Parkinson Disease. Plos One. 2012; 7(5)

26. [Accessed June 2010.] Public Use Microdata Series (IPUMS-USA) Occupation Code System. 2000. http://usa.ipums.org/usa/volii/00occup.shtml

27. Young HA, Mills PK, Riordan D, Cress R. Use of a crop and job specific exposure matrix for estimating cumulative exposure to triazine herbicides among females in a case-control study in the Central Valley of California. Occup Environ Med. 2004; 61:945-951. [PubMed: 15477289]

28. Elbaz A, Tranchant C. Epidemiologic studies of environmental exposures in Parkinson's disease. J Neurol Sci. 2007; 262:37-44. [PubMed: 17673256]

29. Hertzman C, Wiens M, Bowering D, Snow B, Calne D. Parkinson's disease: a case-control study of occupational and environmental risk factors. Am J Ind Med. 1990; 17:349-355. [PubMed: 2305814]

30. Ho SC, Woo J, Lee CM. Epidemiologic study of Parkinson's disease in Hong Kong. Neurology. 1989; 39:1314-1318. [PubMed: 2797455]

31. Golbe LI, Farrell TM, Davis PH. Follow-up study of early-life protective and risk factors in Parkinson's disease. Mov Disord. 1990; 5:66-70. [PubMed: 2296261]

32. van der Mark M, Brouwer M, Kromhout H, Nijssen P, Huss A, Vermeulen R. Is Pesticide Use Related to Parkinson's Disease? Some Clues to Heterogeneity in Study Results. Environ Health Perspect. 2012; 120:340-347. [PubMed: 22389202] 
33. Nanni O, Ricci M, Lugaresi C, Amadori D, Falcini F, Buiatti E. Iterative use of a priori exposure matrices to improve the characterization of chemical exposures in agricultural work studies. Scand J Work Environ Health. 1993; 19:191-199. [PubMed: 8367697]

34. Ward MH, Lubin J, Giglierano J, et al. Proximity to crops and residential exposure to agricultural herbicides in iowa. Environ Health Perspect. 2006; 114:893-897. [PubMed: 16759991]

35. Miligi L, Settimi L, Masala G, et al. Pesticide exposure assessment: a crop exposure matrix. The Working Group on Pesticide Exposure Assessment. Int J Epidemiol. 1993; 22 (Suppl 2):S42-45. [PubMed: 8132391]

36. Rugbjerg K, Harris MA, Shen H, Marion SA, Tsui JKC, Teschke K. Pesticide exposure and risk of Parkinson's disease-a population-based case-control study evaluating the potential for recall bias. Scand J Work Environ Health. 2011; 37:427-436. [PubMed: 21240453]

37. Lange JH, Buja A, Mastrangelo G. Endotoxin, a possible agent in the causation of Parkinson's disease. J Occup Environ Med. 2006; 48:655. author reply 655-656. [PubMed: 16832216]

38. Dosemeci M, Alavanja MC, Rowland AS, et al. A quantitative approach for estimating exposure to pesticides in the Agricultural Health Study. Ann Occup Hyg. 2002; 46:245-260. [PubMed: 12074034]

39. Stewart PA, Prince JK, Colt JS, Ward MH. A method for assessing occupational pesticide exposures of farmworkers. Am J Ind Med. 2001; 40:561-570. [PubMed: 11675625]

40. Menzie CM. Fate of pesticides in the environment. Annu Rev Entomol. 1972; 17:199-222. [PubMed: 4550533]

41. Zweig G, Gao R, Popendorf W. Simultaneous dermal exposure to captan and benomyl by strawberry harvesters. J Agric Food Chem. 1983; 31:1109-1113. [PubMed: 6630743] 


\section{Table 1}

Sociodemographic characteristics of study population in Central Valley of California, 2001-2011

\begin{tabular}{|c|c|c|c|c|}
\hline & \multicolumn{2}{|c|}{ PD Cases } & \multicolumn{2}{|c|}{ Controls } \\
\hline & $(\mathrm{N}=357)$ & $\%$ & $(\mathrm{~N}=750)$ & $\%$ \\
\hline \multicolumn{5}{|l|}{ Age } \\
\hline Mean and STD & 68.29 & \pm 10.22 & 66.89 & \pm 11.18 \\
\hline Range & $34-88$ & & $35-99$ & \\
\hline$\geq 50$ years & 336 & 94 & 700 & 93 \\
\hline \multicolumn{5}{|l|}{ Sex } \\
\hline Male & 205 & 57 & 350 & 47 \\
\hline Female & 152 & 43 & 400 & 53 \\
\hline \multicolumn{5}{|c|}{$1^{\text {st }}$ Degree Relative with PD } \\
\hline No & 305 & 85 & 687 & 92 \\
\hline Yes & 52 & 15 & 63 & 8 \\
\hline \multicolumn{5}{|l|}{ Race } \\
\hline White & 287 & 80 & 524 & 70 \\
\hline Non-White & 70 & 20 & 224 & 30 \\
\hline Hispanic & 47 & 13 & 143 & 19 \\
\hline Black & 3 & 1 & 24 & 3 \\
\hline Asian & 4 & 1 & 22 & 3 \\
\hline Native American & 16 & 4 & 35 & 5 \\
\hline \multicolumn{5}{|l|}{ Education } \\
\hline$<12 \mathrm{yrs}$ & 66 & 18 & 111 & 15 \\
\hline$=12 \mathrm{yrs}$ & 96 & 27 & 155 & 21 \\
\hline$>12 \mathrm{yrs}$ & 195 & 55 & 484 & 64 \\
\hline \multicolumn{5}{|l|}{ Smoking Status } \\
\hline Never smoker & 187 & 52 & 363 & 49 \\
\hline Former smoker & 150 & 42 & 302 & 40 \\
\hline Current smoker & 20 & 6 & 85 & 11 \\
\hline
\end{tabular}

a. Race was missing for 2 controls 


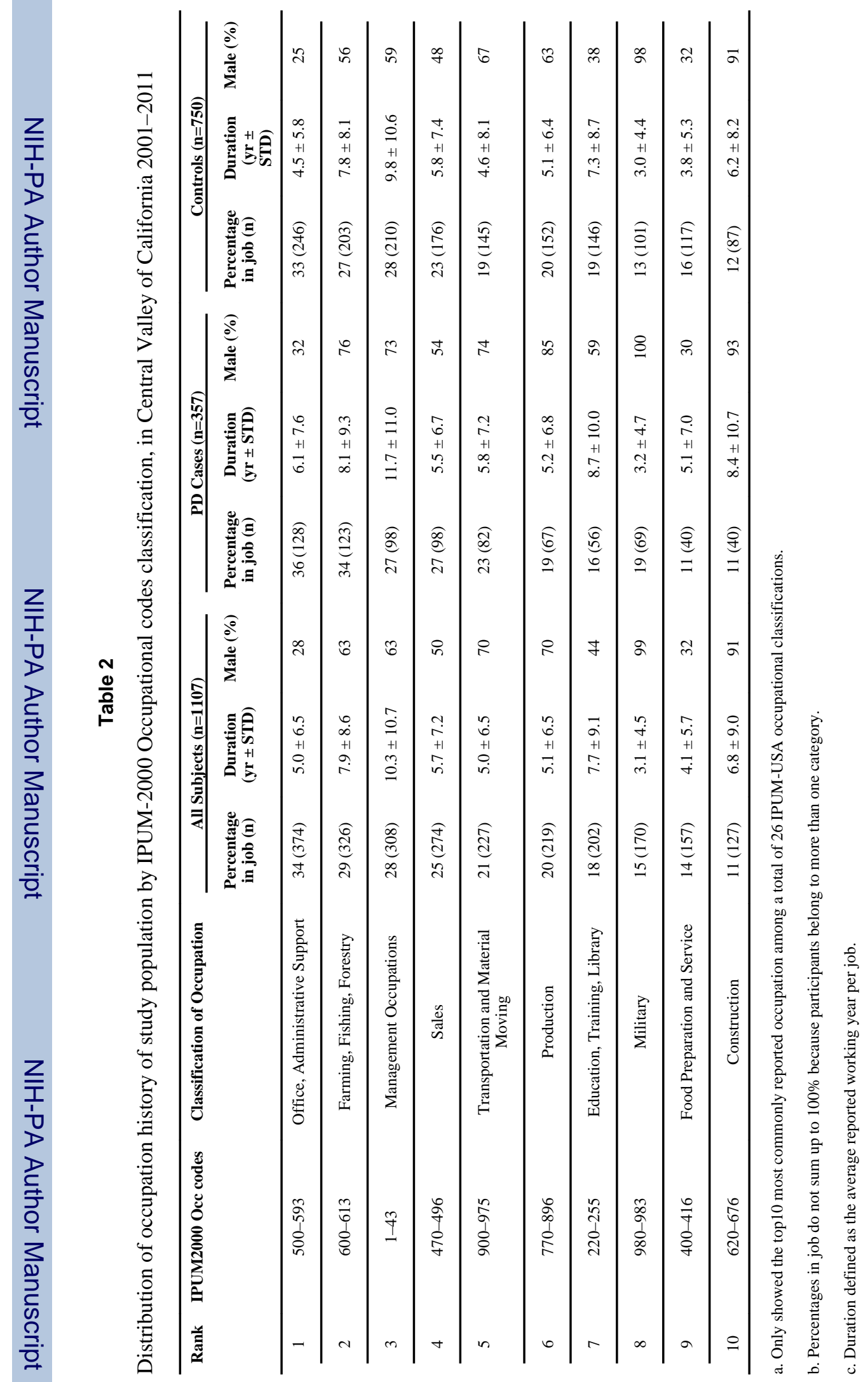




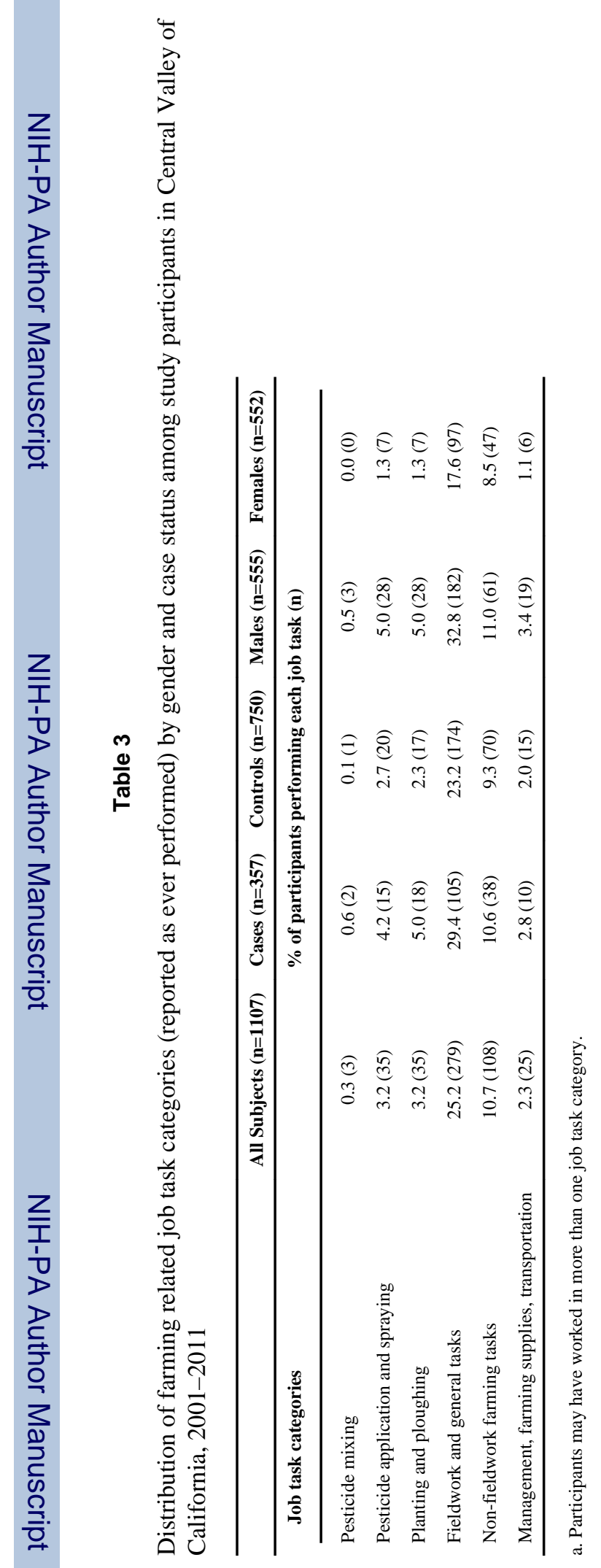

Arch Environ Occup Health. Author manuscript; available in PMC 2015 January 01. 


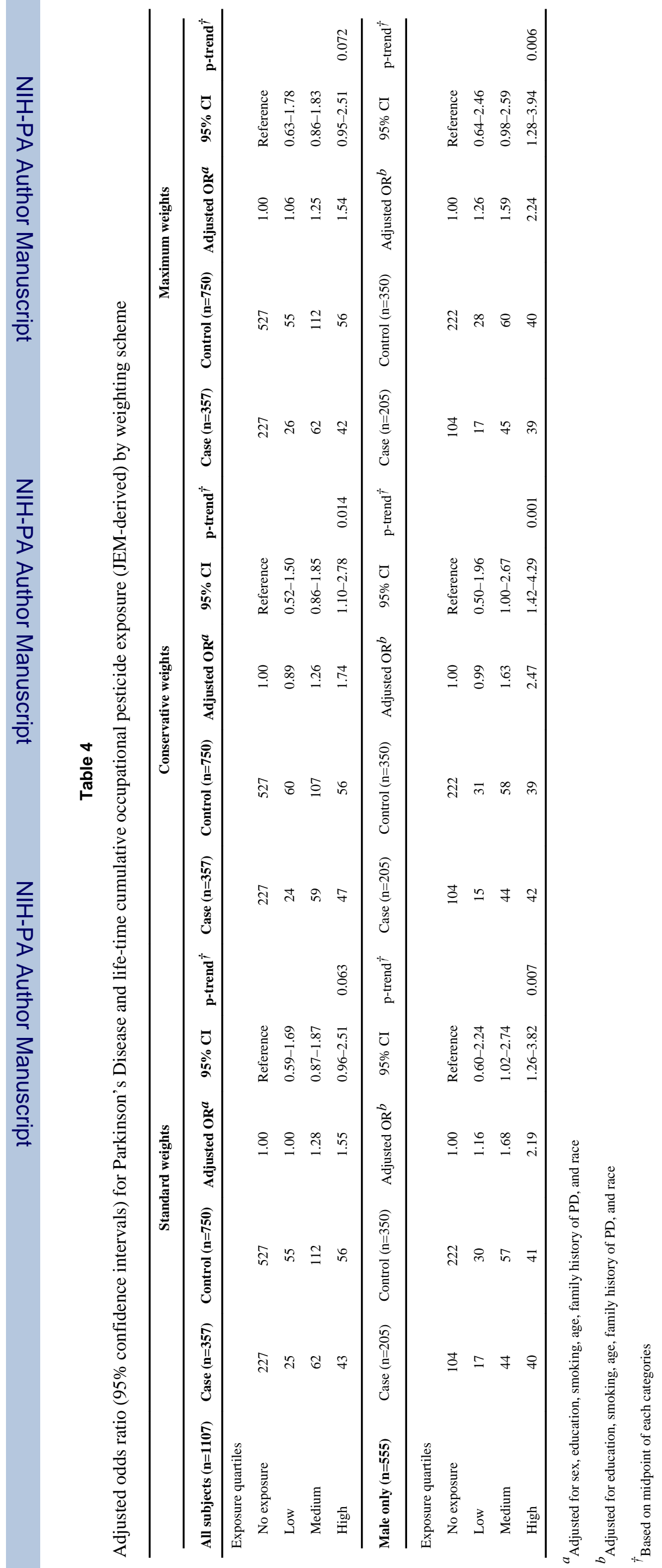




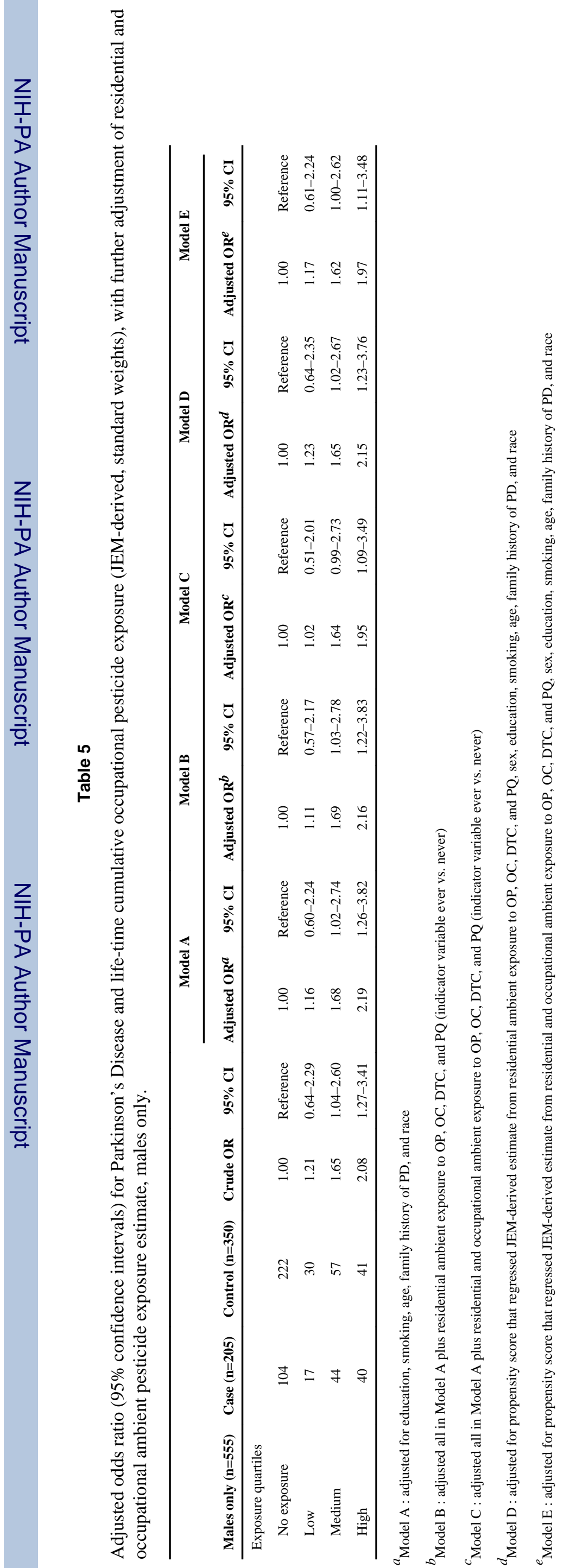




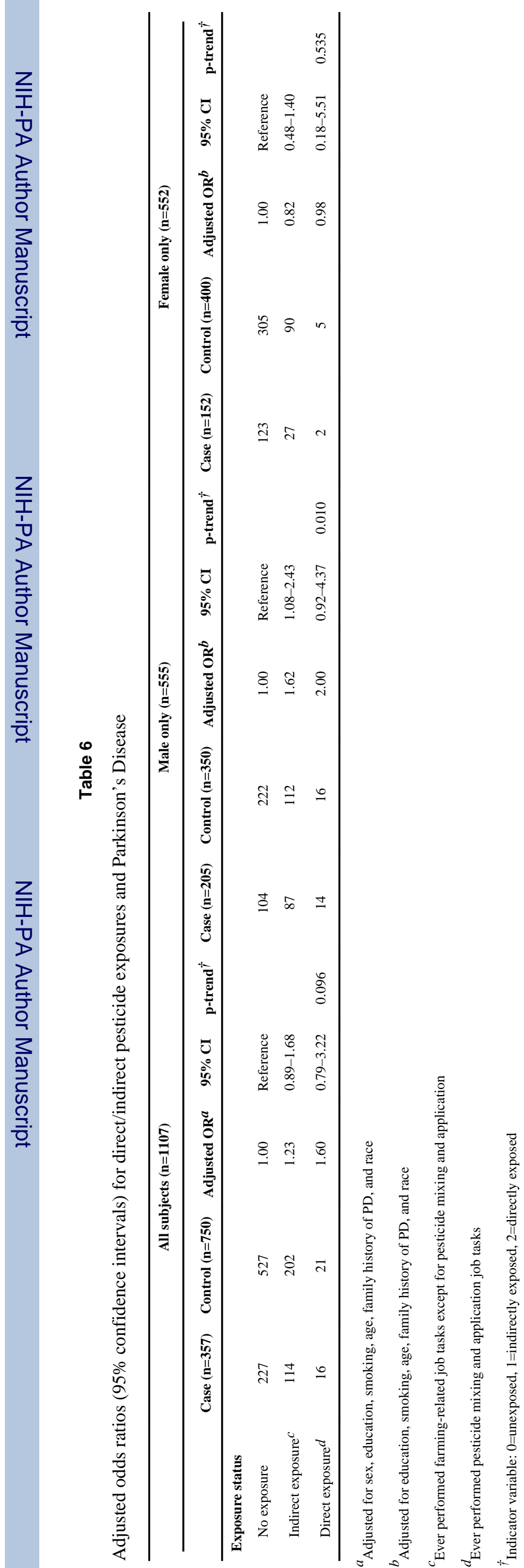

